\title{
Effect of time to electrocardiogram on time from electrocardiogram to fibrinolysis in acute myocardial infarction patients
}

\author{
Clare L. Atzema, MD, MSc ${ }^{*}$; Peter C. Austin, PhD*; Jack V. Tu, MD, MSc, PhD*; \\ Michael J. Schull, MD, MSc ${ }^{* \dagger}$
}

\section{ABSTRACT}

Objective: The American Heart Association (AHA) recommends a benchmark door-to-electrocardiogram (ECG) time of 10 minutes for acute myocardial infarction patients, but this is based on expert opinion (level of evidence C). We sought to establish an evidence-based benchmark door-toECG time.

Methods: This retrospective cohort study used a populationbased sample of patients who suffered an ST elevation myocardial infarction (STEMI) in Ontario between 1999 and 2001. Using cubic smoothing splines, we described (1) the relationship between door-to-ECG time and ECG-to-needle time and (2) the proportion of STEMI patients who met the benchmark door-to-needle time of 30 minutes based on their door-to-ECG time. We hypothesized nonlinear relationships and sought to identify an inflection point in the latter curve that would define the most efficient (benefit the greatest number of patients) door-to-ECG time.

Results: In 2,961 STEMI patients, the median door-to-ECG and ECG-to-needle times were 8.0 and 27.0 minutes, respectively. There was a linear increase in ECG-to-needle time as the door-to-ECG time increased, up to approximately 30 minutes, after which the ECG-to-needle time remained constant at 53 minutes. The inflection point in the probability of achieving the benchmark door-to-needle time occurred at 4 minutes, after which it decreased linearly, with every minute of door-to-ECG time decreasing the average probability of achievement by $2.2 \%$.

Conclusions: Hospitals that are not meeting benchmark reperfusion times may improve performance by decreasing door-to-ECG times, even if they are meeting the current AHA benchmark door-to-ECG time. The highest probability of meeting the reperfusion target time for fibrinolytic administration is associated with a door-to-ECG time of 4 minutes or less.

\section{RÉSUMÉ}

Objectif: L'American Heart Association (AHA) recommande un délai de 10 minutes depuis l'arrivée du patient jusqu'à l'électrocardiogramme (délai " entre l'arrivée et I'ECG ") dans les cas d'infarctus aigu du myocarde (IAM), mais cette recommandation est basée sur l'opinion d'experts (niveau de preuve " $C$ "). Nous avons cherché à établir un délai " entre l'arrivée et l'ECG " fondé sur les données probantes.

Méthode: Nous avons réalisé une étude de cohorte rétrospective auprès d'un échantillon représentatif de patients ayant subi un infarctus du myocarde avec sus-décalage du segment ST (STEMI) en Ontario entre 1999 et 2001. Nous avons utilisé des splines cubiques de lissage pour décrire (1) la relation entre le délai " entre l'arrivée et l'ECG " et " entre I'ECG et l'injection " et (2) la proportion de patients présentant un STEMI traités dans un délai de 30 minutes " entre l'arrivée et l'injection " selon leur délai " entre l'arrivée et l'ECG ". Nous avons émis des hypothèses de relations non linéaires et cherché à déterminer le point d'inflexion dans la courbe de probabilité définissant le délai « entre l'arrivée et I'ECG » le plus efficace (c'est-à-dire bénéficiant le plus grand nombre de patients).

Résultats: Chez 2961 patients présentant un STEMI, les délais médians " entre l'arrivée et I'ECG " et " entre I'ECG et I'injection " étaient de 8,0 et de 27,0 minutes, respectivement. On rapporte une augmentation linéaire du délai " entre I'ECG et l'injection " avec l'augmentation du délai " entre I'arrivée et I'ECG ", jusqu'à environ 30 minutes, après quoi le délai " entre I'ECG et I'injection " demeurait constant à 53 minutes. Le point d'inflexion de la probabilité d'atteindre le

\footnotetext{
From the *Institute for Clinical Evaluative Sciences, Toronto, ON; †Division of Emergency Medicine, Department of Medicine, University of Toronto and Sunnybrook Health Sciences Centre, Toronto, ON; and ‡Division of General Internal Medicine, Department of Medicine, University of Toronto and Sunnybrook Health Sciences Centre, Toronto, ON.
}

Correspondence to: Dr. Clare L. Atzema, Institute for Clinical Evaluative Sciences, 2075 Bayview Avenue, Room G147, Toronto, ON M4N 3M5; clare.atzema@ices.on.ca.

Submitted January 8, 2010; Revised March 23, 2010; Accepted March 26, 2010

This article has been peer reviewed.

(c) Canadian Association of Emergency Physicians 
délai de référence " entre l'arrivée et l'injection " se situait à 4 minutes. Passé ce point, il diminuait de façon linéaire, chaque minute de réduction du délai " entre l'arrivée et I'ECG " réduisant la probabilité moyenne de réussite de $2,2 \%$.

Conclusion: Les hôpitaux qui n'atteignent pas les délais de reperfusion peuvent améliorer les résultats en diminuant les délais " entre I'arrivée et I’ECG ", même s'ils atteignent le délai actuel " entre l'arrivée et l'ECG " recommandé par I'AHA. La plus forte probabilité d'atteindre le délai ciblé de reperfusion pour la fibrinolyse est associée à un délai " entre I'arrivée et l'ECG » de 4 minutes ou moins.

Keywords: acute myocardial infarction, benchmark times, door-to-electrocardiogram, emergency department, fibrinolysis
Coronary artery disease remains the leading cause of death in Canada ${ }^{1}$ and the United States, ${ }^{2}$ and chest pain is the second most common reason to present to an emergency department (ED), with 6 million visits annually in the United States. ${ }^{3}$ The American Heart Association (AHA) recommends that patients presenting with chest discomfort or chest pain equivalent receive an electrocardiogram (ECG) within 10 minutes of ED arrival. ${ }^{4,5}$ Less than $10 \%$ of ED visits for chest pain ultimately prove to be an acute myocardial infarction (AMI), ${ }^{6,7}$ and to identify AMI patients among all the patients with chest pain (and the $33 \%$ of AMI patients who present without chest pain ${ }^{8}$ ), a very large number of patients must receive an ECG within 10 minutes of arrival. Given the high prevalence of ED crowding in the Western world, ${ }^{9-11}$ diverting resources to care for one group of patients, such as potential AMI patients, may occur at the expense of other groups. Thus, it is imperative that recommended benchmarks are evidence based and as efficient as possible.

The benchmark door-to-ECG time of 10 minutes is based on expert opinion (level of evidence C). ${ }^{3}$ The goal underlying the acquisition of an early ECG is to provide proven therapies to AMI patients in a timely way to reduce subsequent morbidity and mortality. ${ }^{12,13}$ Currently, only approximately half of AMI patients receive reperfusion therapies within the benchmark times. $^{14-16}$ We hypothesized that the relationship between door-to-ECG time and ECG-to-needle time is nonlinear; that is, patients whose initial ECG is delayed may have an even longer delay before definitive treatment owing to multiple, possibly additive factors. The initial impression of a lower acuity illness may be pervasive and protracted: we hypothesized that a delay in acquisition of the initial ECG is associated with further delays before reperfusion therapy is administered owing to the complex nature of the ED system of care and the variable presentation of AMIs. To our knowledge, no study has looked at the relationship between the door-to-ECG time and ECG-to-needle time. Furthermore, if the relationship is nonlinear, a critical threshold in doorto-ECG time may exist, after which far fewer patients meet the AHA benchmark time to reperfusion.

The primary objectives of this study were the following: (1) to describe the relationship between door-to-ECG time and ECG-to-needle time and (2) to estimate the proportion of patients who meet the benchmark door-to-needle time based on their door-toECG time, with the goal of defining the most efficient benchmark door-to-ECG time. Our secondary objective was to examine whether the door-to-ECG time has an independent effect on ECG-to-needle time.

\section{METHODS}

\section{Study Design}

This is retrospective cohort study using a populationbased sample of ST elevation myocardial infarction (STEMI) patients in the province of Ontario for the period of April 1999 to March 2001. Ethics approval was obtained from the Institute for Clinical Evaluative Sciences (ICES).

\section{Data Sources}

The Enhanced Feedback for Effective Cardiac Treatment (EFFECT) study contains a populationbased sample of AMI patients from the province of Ontario. It has been described in detail elsewhere. ${ }^{17,18}$ It includes clinical data from retrospective chart reviews of 11,510 AMI patients discharged from 103 acute care hospitals in Ontario from April 1999 to March 2001. All but one of the 85 eligible hospital corporations in Ontario that treated 30 or more AMI patients per year agreed to participate. Chart reviews were performed by trained nurse abstractors using a standardized data collection instrument (data were entered directly into notebook computers using an 
EFFECT Microsoft Access application) on up to 125 randomly selected AMI patients per hospital or all AMI patients at that hospital if there were fewer than 125 . Prespecified chart review rules were delineated in a detailed EFFECT chart abstraction operations manual that each nurse was given. Interrater reliability was assessed in $5 \%$ of charts and demonstrated high reliability for all of the indicators assessed by EFFECT. ${ }^{19}$ Income quintile was derived from census data.

\section{Inclusion and Exclusion Criteria}

The inclusion and exclusion criteria of EFFECT patients, as well as the rationale for them, are described elsewhere. ${ }^{20}$ In brief, EFFECT includes Ontario residents between the ages of 20 and 105 years with a valid Ontario Health Card number who were admitted to an acute care hospital with a "most responsible diagnosis" of AMI (defined in the Canadian Institutes of Health Information Discharge Abstract Database as the diagnosis responsible for the greatest portion of the patient's length of stay in hospital). The diagnosis of AMI was confirmed using the European Society of Cardiology/American College of Cardiology clinical criteria of AMI, which include the presence of any two of the following: ECG changes, symptoms, and positive enzymes. ${ }^{21}$ Patients were excluded if the AMI was an in-hospital complication. Patients who were transferred to a second site were counted only once based on their first ED of admission. In the current study, only STEMI patients were included; patients with a nondiagnostic initial ECG (for STEMI) were excluded, as were patients whose initial therapy was percutaneous coronary intervention (PCI) (because relatively few patients in EFFECT had primary PCI). ${ }^{17,18}$

\section{Outcome Measures}

Primary outcome measures were the following: (1) the relationship between door-to-ECG time and ECG-toneedle time and (2) proportion of patients who met the benchmark door-to-needle time for every minute of door-to-ECG time. Door-to-ECG time was defined as the interval between the time of arrival at the ED and the time of the initial ECG. ECG-to-needle time was the interval between the time of the initial ECG and the time when the fibrinolysis infusion was started. The time of arrival in the ED was defined in EFFECT as the time the patient was seen by a triage nurse in the ED (triage occurs before registration in Canada, as in the United States); the time of the initial ECG was taken from the ECG, which uses a clock internal to the ECG machine. The time of fibrinolysis infusion was taken from the ED chart. A STEMI was defined as either $\geq 1 \mathrm{~mm}$ ST-segment elevation in two contiguous ECG leads or a new (not known to be old) left bundle branch block (BBB) with concurrent chest pain. ${ }^{4}$

\section{Predictor Variables}

In the secondary analysis, the predictor variable of interest was door-to-ECG time. Seventeen covariants that could be potential confounders in the relationship between door-to-ECG time and ECG-to-needle time were included in the regression model. These included patient demographics (age, sex, socioeconomic status from median neighbourhood household income), clinical features on arrival (systolic blood pressure, heart rate, respiratory rate, shortness of breath, cardiac arrest or shock, pulmonary edema), hospital factors (type of hospital, yearly ED AMI volumes, presence of a catheterization laboratory on site), and contextual factors (location of fibrinolysis, BBB or paced rhythm on initial ECG, arrival by ambulance, arrival time of day, and day of week). Cardiac arrest was documented if it occurred in the 6 hours prior to or 10 minutes after arrival in the ED, as documented by a physician. The type of hospital was documented as a teaching hospital or not, and the location of fibrinolysis was ED or other (cardiac care unit or ward). The mode of arrival was either by ambulance or ambulatory.

\section{Data Analyses}

To describe the relationship between door-to-ECG time and ECG-to-needle time, we used cubic smoothing splines with five knots to model the relationship between door-to-ECG time (on the $x$ axis) and ECG-to-needle time (on the $y$-axis), given that we did not expect the relationship to be linear. The location of the knots was determined using the criteria of Herndon and Harrell. ${ }^{22}$ Next, we used logistic regression to determine the relationship between door-to-ECG time and the probability of meeting the AHA benchmark door-to-needle time of 30 minutes; this analysis was restricted to subjects with a door-to-ECG time up to 29 minutes (after 
which it would be impossible to meet the 30-minute benchmark door-to-needle time). In this model, the effect of door-to-ECG time was modeled using cubic smoothing splines as above. We plotted the modelderived predicted probabilities of meeting the doorto-needle benchmark time of 30 minutes against the door-to-ECG time, which allowed us to identify an inflection point, or the point of greatest change in the slope of the curve. This point represents a door-toECG time after which the number of patients who meet the benchmark door-to-needle time rapidly declines.

To meet the secondary objective, the independent effect of door-to-ECG time on ECG-to-needle time was assessed using quantile regression modeling. ${ }^{23}$ Quantile regression models the effect of the predictor variables on the median of the dependent variable instead of the mean. Quantile regression is particularly suited to distributions that are susceptible to being skewed. In this study, we modeled the effect of the door-to-ECG time and 21 covariants on the median ECG-to-needle time. Bootstrap resampling was used to estimate standard errors and confidence intervals. Quantile regression was performed with Stata software version 9 (StataCorp, College Station, TX), whereas all other analyses were done with $S A S$ software version 9.1 (SAS Institute Inc., Cary, NC).

\section{RESULTS}

There were 2,961 STEMI patients with a diagnostic initial ECG and a door-to-ECG and door-to-needle time during the study time period. The mean age was 62.7 years (SD \pm 13.1 years), and $70.9 \%$ were male (Table 1 ). The median door-to-ECG time of the cohort was 8.0 minutes (IQR 4.0-15.0 minutes). The median door-toneedle time was 39.0 minutes (IQR 25.0-66.0 minutes). The median ECG-to-needle time was 27.0 minutes (IQR $16.0-50.0$ minutes). The 30 -day mortality rate was $8.0 \%$ (95\% CI 7.1-9.0).

The relationship between door-to-ECG time and ECG-to-needle time is shown in Figure 1. The smoothed line shows a gradual increase in ECG-toneedle time as the door-to-ECG time increases: from 0 to 15 to 30 minutes, the ECG-to-needle time increases from 38 to 47 to $52 \frac{1 / 2}{2}$ minutes, respectively. The slope flattens for door-to-ECG times greater than 30 minutes: ECG-to-needle time remains constant at about 53 minutes, as shown in Figure 2.
Table 1. Baseline characteristics of the study cohort, 2,961 ST elevation myocardial infarction (STEMI) patients

Characteristic n (\%)

Patient demographics

Mean age $\pm S D$, yr

$62.7 \pm 13.1$

Male (4 patients unknown)

Income quintile (28 patients unknown)

1

2

3

4

5

$2,097(70.9)$

$557(19.4)$

620 (21.5)

$594(20.6)$

$600(20.8)$

$508(17.7)$

Presenting clinical examination factors

Systolic blood pressure, mean (SD)

$143(33)$

$76(21)$

20 (5)

Respiratory rate, mean (SD)

Shortness of breath

$598(20.2)$

Cardiac arrest or shock

Acute pulmonary edema

$143(4.8)$

$79(2.7)$

Past medical history

Hypertension

Diabetes mellitus

$1,153(38.9)$

$538(18.2)$

$915(30.9)$

Hypercholesterolemia

Smoking

$1,304(44.0)$

Coronary artery disease

874 (29.5)

$157(5.3)$

$47(1.6)$

Congestive heart failure

Contextual factors

Arrival by ambulance

Time of day

Day (08:00-16:00)

Evening (16:01-00:00)

Night (00:01-08:00)

$1,310(44.2)$

$1,270(42.9)$

934 (31.5)

$787(25.6)$

Day of week

Weekend

$891(30.1)$

Lytic administerd in ED

Lytic administerd by emergency physician

$2,460(83.1)$

$1,954(66.0)$

Hospital factors

Hospital type

Teaching (12 sites)

280 (9.5)

Community (78 sites)

$2,443(82.5)$

Small (12 sites)

Catheterization hospital (12 sites)

$238(8.0)$

$148(5.0)$

ED AMI volume*

Very low (7 sites)
Low ( 21 sites)
Moderate ( 17 sites)
High (15 sites)
Very high ( 42 sites)

$115(3.9)$

$586(19.8)$

$585(19.7)$

$414(14.0)$

$1,261(42.6)$

$\mathrm{AMI}=$ acute myocardial infarction $*^{*}$ very low < 50/year: low 51-100/year: moderate 101-200/year, high 201-300/year; very high 301+/year); CABG = coronary artery bypass graft; $E D=$ emergency department. 


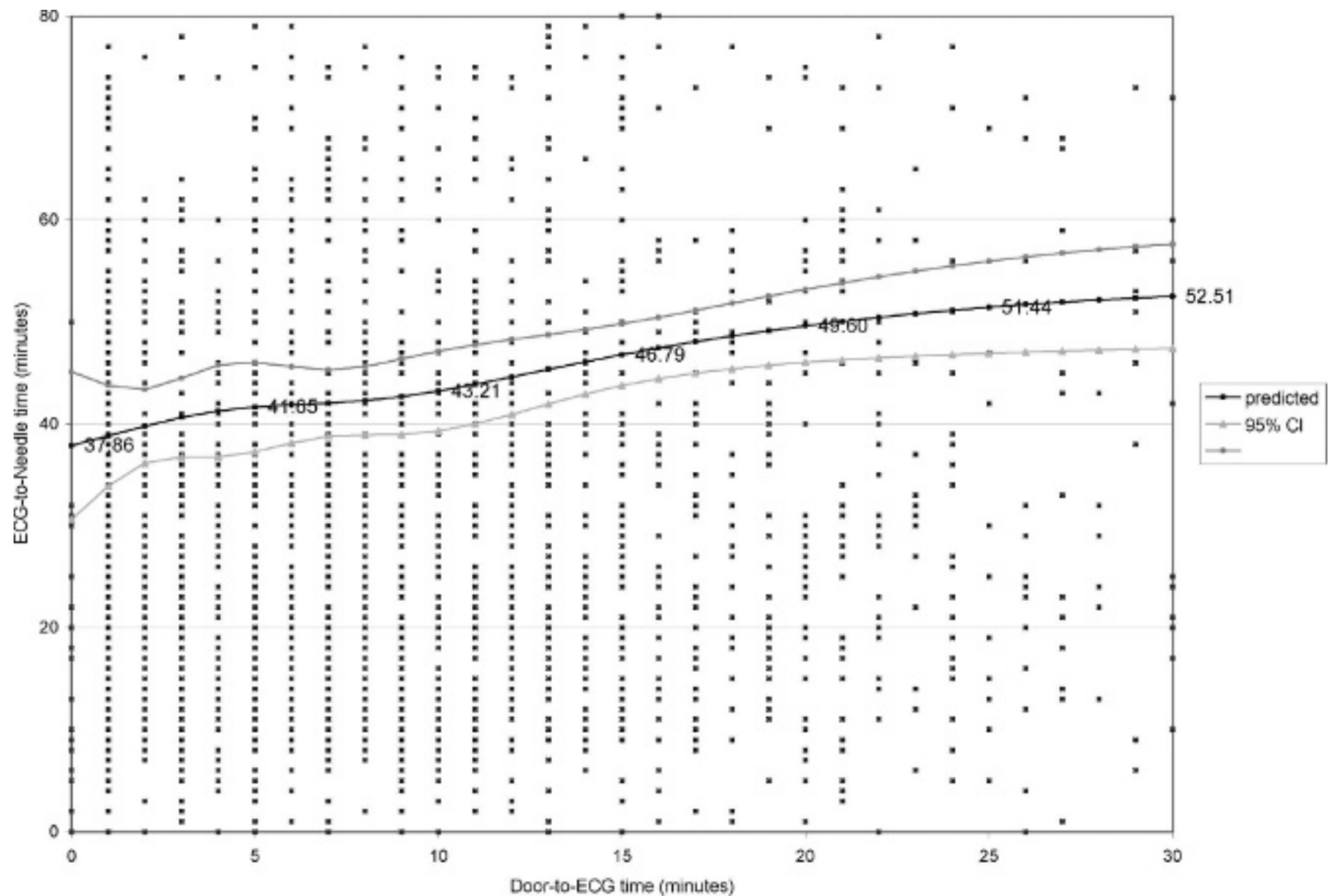

Figure 1. Relationship between door-to-electrocardiogram (ECG) time (0-30 minutes) and ECG-to-needle time with 95\% Cls for door-to-ECG times up to 30 minutes, using cubic smoothing splines with five knots.

The probability of meeting the benchmark doorto-needle time of 30 minutes, for a given door-toECG time, is shown in Figure 3. If the initial ECG was completed within 0 to 4 minutes, the predicted probability of achieving the benchmark door-toneedle time was relatively constant at approximately $60 \%$. Then the predicted probability decreased in a relatively linear fashion: an inflection point occurred at 4 minutes. Beyond this door-to-ECG time, the chances of meeting the benchmark door-to-needle time decreased to $36 \%$ (95\% CI 33-40) by a door-toECG time of 10 minutes, to $24 \%$ (95\% CI 21-28) at 15 minutes, and to $12 \%$ (95\% CI 9-16) at 20 minutes. For each minute increase in door-to-ECG time, the average decrease in the probability of meeting the benchmark door-to-needle time dropped by $2.2 \%$.

In the secondary analysis, the adjusted effect of door-to-ECG time on median ECG-to-needle time was statistically, but not clinically, significant. For every minute increase in door-to-ECG time, the median ECG-to-needle time increased by 4.8 seconds $(p=0.025)$. Other statistically significant independent predictors of an increased median ECG-to-needle time are shown in Figure 4 and included older age, overnight arrival time, a nondiagnostic rhythm (paced or BBB on ECG), fibrinolysis performed outside the ED (ie, in the cardiac care unit or ward), and decision to thrombolyse made by the consultant. Male sex, a higher income quintile, presenting in cardiac arrest or shock, arrival by ambulance, and being seen at a higher ED AMI volume centre were associated with significantly shorter ECG-to-needle times.

\section{DISCUSSION}

In contrast to our study hypothesis, we found that the time between the initial ECG and fibrinolysis increased gradually and linearly until door-to-ECG times of about 30 minutes and then remained essentially constant at approximately 53 minutes for longer door-to-ECG times. Thus, there is a linear, incremental benefit to door-to-ECG times of 30 minutes or less in terms of 


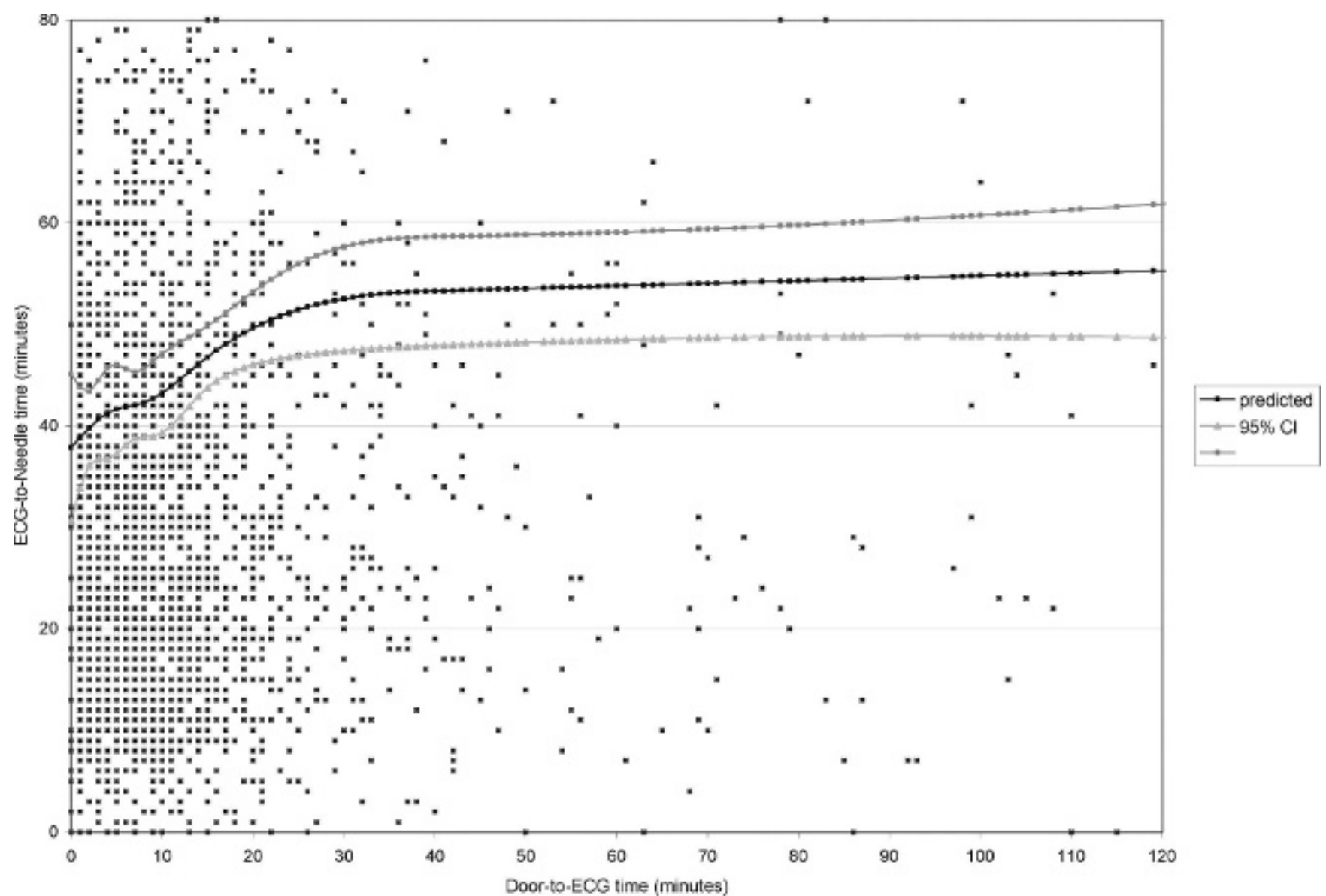

Figure 2. Relationship between door-to-electrocardiogram (ECG) time (0-120 minutes) and ECG-to-needle time with 95\% Cls for door-to-ECG times up to 30 minutes, using cubic smoothing splines with five knots.

minutes saved in ECG-to-needle time. After 30 minutes, fibrinolysis occurs within a relatively constant time period. In addition, we found that the proportion of patients who met the AHA benchmark door-to-needle time decreased in a relatively linear fashion after the initial 3 to 4 minutes of door-to-ECG time. The inflection point in the curve occurred at 4 minutes, a target that may not be feasible for all hospitals. Although 4 minutes may represent an ideal door-to-ECG time, it may be more realistic to emphasize that the sooner the initial ECG is done, the better a patient's chances of receiving fibrinolysis within the benchmark time. It also suggests that hospitals not meeting the benchmark reperfusion times should focus on further reducing their door-to-ECG times even if they routinely meet the 10-minute door-to-ECG time benchmark.

Achieving an ambitious target door-to-ECG time of 4 minutes may be possible through two means: the implementation of triage ECGs or ECGs performed during the ED triage assessment (the patient's first point of contact in the ED) and prehospital ECGs (for those who arrive by ambulance). Triage ECGs have been used at many academic hospitals in the last decade ${ }^{24}$ and are likely the only feasible method to achieve door-to-ECG times of 4 minutes. There are limited data on the utility of triage ECGs: one study surveyed 365 US hospitals and found that having written criteria for obtaining an immediate ED ECG and a dedicated ECG triage space was not independently associated with shorter door-toballoon times. ${ }^{24}$ Another multicentre study assessed the impact of hospital use of triage ECGs on rates of lowacuity ED triage of AMI patients and also found no association. ${ }^{25}$ At the patient level, a single-centre study found that performing a triage ECG on patients with one of five presenting complaints decreased mean door-toECG times by 4 minutes (from 10 minutes to 6 minutes) and door-to-needle times by 11 minutes. However, this was at the cost of performing 1\% more ECGs in all ED patients (from 6.3 to $7.3 \%$ ). ${ }^{26}$ We noted that in crowded EDs, triage ECGs may further delay the triage of other patients, particularly if they require time for the triage nurse to show the ECG to the physician. Like cardiac 


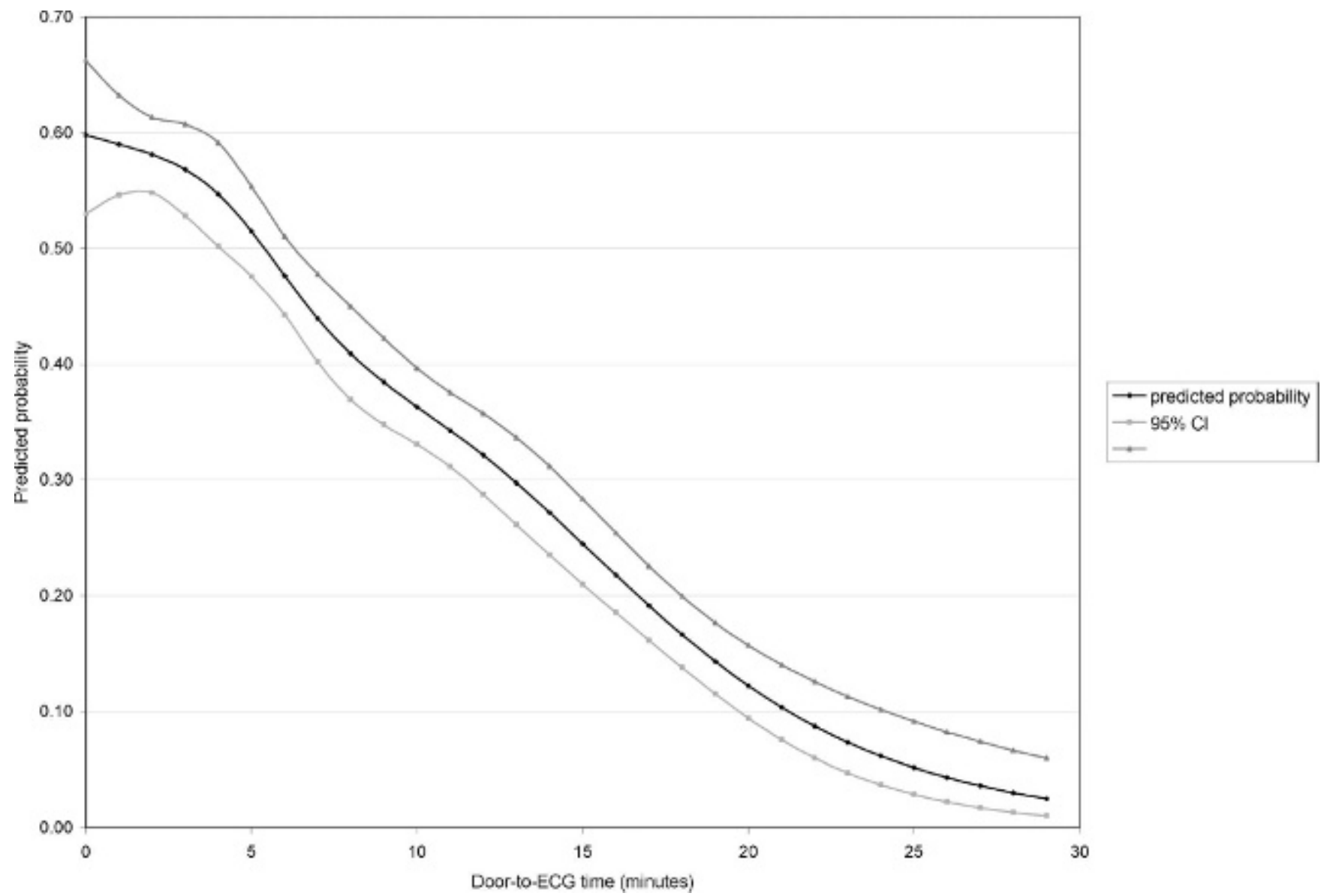

Figure 3. Predicted probability of meeting benchmark door-to-needle time (of 30 minutes) with $95 \%$ Cls, based on door-toelectrocardiogram (ECG) time.

care unit nurses, triage nurses could be trained to interpret ECGs ${ }^{27}$ and computerized ECG readings have been used in the prehospital setting, with a high specificity of STEMI detection. ${ }^{28,29}$ Further research is needed to elucidate the benefits and drawbacks of triage ECGs; however, they are one potential solution to gaining further reductions in door-to-ECG times, particularly for a very early target such as 4 minutes.

Prehospital ECGs have been recommended by the AHA because they decrease reperfusion times, ${ }^{30}$ but only about half of AMI patients arrive by ambulance. ${ }^{31}$ Research into improving the rate at which AMI patients call for an ambulance has been extensive but unsuccessful; thus, the utility of the prehospital ECG applies to only one half of AMI patients. Although one survey found that $90 \%$ of US emergency medical systems (EMSs) have ECG equipment, ${ }^{32}$ the use of prehospital ECGs has been patchy across the United States and Canada $^{33}$ : less than $10 \%$ of STEMI patients receive a prehospital ECG. ${ }^{31}$ Diagnostic quality prehospital ECGs increase on-scene time by an average of 5 to 6 minutes, ${ }^{30}$ similar to the target door-to-ECG time derived in this study. It is likely that as more EMSs adopt an integrated system of care for STEMI patients with regional hospitals, more patients will meet this target. For the other half of AMI patients who do not call an ambulance, the ED must be the focus of shorter times to initial ECG acquisition.

In our secondary analyses, we found that the adjusted door-to-ECG time did not have a clinically significant effect on the ECG-to-needle time. Instead, a variety of other variables affected the length of time between completion of the initial ECG and initiation of reperfusion. Although previous studies have not assessed the specific time period between ECG and fibrinolysis, there is substantial research on predictors of door-to-needle time (arrival to fibrinolysis). Previous research has shown that older age delays fibrinolysis, ${ }^{34-36}$ consistent with our findings; this may be due in part to less clear symptom presentation and perhaps because clinicians are reluctant to thrombolyse a group with higher bleeding risks. In our 


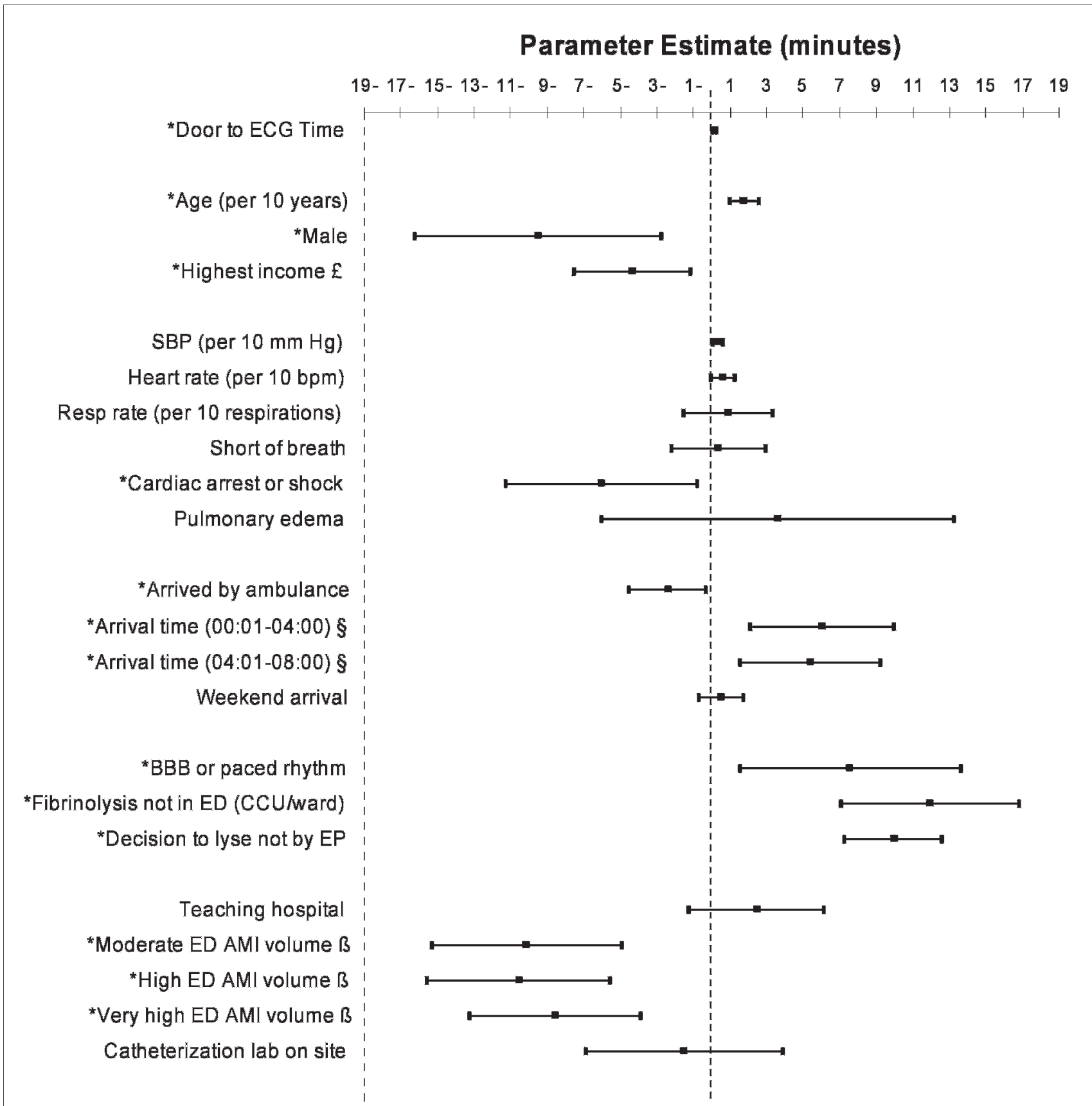

Figure 4. Quantile regression analysis of predictors of electrocardiogram (ECG)-to-needle time, independent effect in minutes, with $95 \% \mathrm{Cls}$. $\mathrm{AMI}=$ acute myocardial infarction; $\mathrm{BBB}=$ bundle branch block; bpm = beats per minute; CCU = cardiac care unit; $\mathrm{ED}=$ emergency department; $\mathrm{EP}=$ emergency physician; SBP $=$ systolic blood pressure. $\mathrm{f}=$ relative to lowest income quintile group; $\S=$ relative to arrival time of $08: 01-12: 00 ; \beta=$ relative to lowest ED AMI volume group, $<50$ AMI patients seen per year.

study, females had a longer delay between ECG and fibrinolysis, consistent with previous results ${ }^{34,36}$ and likely due in part to atypical symptom presentation. Arriving in the early morning hours also produced a slight delay in ECG-to-needle time, perhaps owing to lower staffing levels. This was not found in the US study by Magid and colleagues, in which time to fibrinolysis was not affected by time of day. ${ }^{37}$ The location and staff performing fibrinolysis delayed ECG-to-needle time, consistent with other studies of door-to-needle time,,$^{35,38,39}$ and a nondiagnostic rhythm on ECG (a BBB or a paced rhythm) also delayed the decision to thrombolyse, ${ }^{34}$ presumably as 
the clinician looks for a comparison ECG. Higher ED AMI volume centres had shorter ECG-to-needle times, consistent with another study. ${ }^{34}$ Interestingly, in our previous work, we found that although higher ED AMI volumes were associated with a higher rate of high-acuity (appropriate) ED triage of AMI patients, ${ }^{40}$ they were also associated with longer door-to-ECG times, ${ }^{25}$ and this study found that these centres are associated with shorter ECG-to-needle times. ${ }^{25}$ This suggests that in high-AMI volume centres, AMI patients are given appropriate highacuity ED triage scores on arrival but often wait to receive their initial ECG, perhaps owing to higher levels of ED crowding. ${ }^{11}$ Once the ECG is completed, however, the time to reperfusion is better than at lower-volume centres, presumably because a proficient system is in place for achieving this step.

\section{LIMITATIONS}

Our results are limited by the age of the data as the patients were thrombolysed in 1999 to 2001; however, the results of several studies with data from 1999 to 2006 suggest that there is no trend of improved door-toECG times. ${ }^{24,41,42}$ A study of 68,439 STEMI patients at over 1,000 US hospitals found no statistically significant improvement in door-to-needle times from 1999 to $2002,{ }^{43}$ whereas a more recent analysis of the National Registry of Myocardial Infarction showed that median door-to-needle times had improved to 29 minutes in $2006,{ }^{15} 10$ minutes less than the 39 minutes found in this study. STEMI patients in the Global Registry of Acute Coronary Events (GRACE) registry had slightly improved median door-to-needle times between 1999 and 2006, from 40 to 34 minutes, although $52 \%$ still had a door-to-needle time of greater than 30 minutes in 2006. ${ }^{14}$ Even with some improvement in door-to-needle times, it is unlikely to have significantly altered the relationship between door-to-ECG time and door-toneedle time.

In recent years, reperfusion therapy has shifted from fibrinolysis to PCI, ${ }^{14}$ yet between 60 and $70 \%$ of AMI patients in the United States present to hospitals without ready access to PCI, ${ }^{44}$ and in Canada, far more patients are treated with fibrinolysis than with PCI. ${ }^{45}$ Thus, studies of fibrinolysis are still very relevant to current clinical care. As well, regardless of the reperfusion modality, the steps preceding it are the same, including acquisition of an ECG. Thus, we believe that the results of this study likely apply to
STEMI patients who receive PCI as well, although the magnitude of the effect likely differs.

At the time of data collection, only one site was completing prehospital ECGs (which were subsequently removed from the analysis), and no sites were performing prehospital fibrinolysis; therefore, the results of this study would not apply to systems that use these techniques. Another limitation was retrospective data collection, with some of the inherent limitations of chart review. However, rigorous training of nurse chart abstractors, standardized data collection instruments, and evaluation of interrater reliability should limit bias. ${ }^{17,18}$ The ED clocks (including the one internal to the ECG machine) were not synchronized; however, this would likely have led to misclassification bias and diminished the strength of our results. Lastly, we were unable to account for ED triage score in our secondary analysis, which has been associated with door-to-ECG and door-to-needle times. ${ }^{25}$

\section{CONCLUSIONS}

The time between the initial ECG in the ED and fibrinolysis increases linearly with increasing delays to performance of the initial ECG, until door-to-ECG times of about 30 minutes, when the ECG-to-needle time reaches a plateau (remains constant). For door-toECG times of greater than 4 minutes, a patient's probability of meeting the benchmark door-to-needle time decreases by several percent for each minute of delay in door-to-ECG time. Triage and prehospital ECGs are likely the only feasible route to achieve an evidence-based target door-to-ECG time of 4 minutes. Future research on triage ECGs is needed.

Acknowledgement: This project was supported in part by a Canadian Institutes of Health Research (CIHR) Team Grant in Cardiovascular Outcomes Research and by an operating grant from the Heart and Stroke Foundation of Ontario (HSFO) (NA5703). Dr. Atzema was supported by a Clinician Scientist Award from the HSFO, Dr. Austin was supported by a Career Investigator Award from the HSFO, and Dr. Tu was supported by a Canada Research Chair in Health Services Research and by a Career Investigator award from the HSFO. Dr Schull was supported by a New Investigator Award from CIHR.

Competing interests: None declared.

\section{REFERENCES}

1. Tu JV, Ghali W, Pilote L, Brien S, editors, Canadian Cardiovascular Outcomes Research Team. Canadian 
cardiovascular atlas. 2006. Available at: http://www.ccort.ca/ CardiovascularAtlas/AtlasdescriptionDownloadAtlas/tabid/ 62/Default.aspx (accessed Jan 7, 2010).

2. American Heart Association. Heart disease and stroke statistics 2008 update. Dallas, Texas: American Heart Association; 2008.

3. National Center for Health Statistics. ED utilization and hospital discharge data; National Hospital Ambulatory Medical Care Survey. 2002. Available at: http://www.cdc.gov/nchs/ data/ad/ad358.pdf (accessed Jan 7, 2010).

4. Antman EM, Anbe DT, Armstrong PW, et al. ACC/AHA guidelines for the management of patients with ST-elevation myocardial infarction-executive summary: a report of the American College of Cardiology/American Heart Association Task Force on Practice Guidelines (Writing Committee to Revise the 1999 Guidelines for the Management of Patients With Acute Myocardial Infarction). Circulation 2004;110:588-636.

5. Krumholz HM, Anderson JL, Brooks NH, et al. ACC/AHA clinical performance measures for adults with ST-elevation and non-ST-elevation myocardial infarction: a report of the American College of Cardiology/American Heart Association Task Force on Performance Measures (Writing Committee to Develop Performance Measures on ST-Elevation and Non-ST-Elevation Myocardial Infarction). 7 Am Coll Cardiol 2006;47:236-65.

6. Kohn MA, Kwan E, Gupta M, et al. Prevalence of acute myocardial infarction and other serious diagnoses in patients presenting to an urban emergency department with chest pain. 7 Emerg Med 2005;29:383-90.

7. Lindsell CJ, Anantharaman V, Diercks D, et al. The Internet Tracking Registry of Acute Coronary Syndromes (i*trACS): a multicenter registry of patients with suspicion of acute coronary syndromes reported using the standardized reporting guidelines for emergency department chest pain studies. Ann Emerg Med 2006;48:666-77, 677.

8. Canto JG, Shlipak MG, Rogers WJ, et al. Prevalence, clinical characteristics, and mortality among patients with myocardial infarction presenting without chest pain. $7 A M A$ 2000;283:3223-9.

9. Derlet R, Richards J, Kravitz R. Frequent overcrowding in U.S. emergency departments. Acad Emerg Med 2001;8:151-5.

10. Proudlove NC, Gordon K, Boaden R. Can good bed management solve the overcrowding in accident and emergency departments? Emerg Med 7 2003;20:149-55.

11. Rowe B, Bond K, Ospina B, et al. Frequency, determinants, and impact of overcrowding on emergency departments in Canada: a national survey of emergency department directors. Ottawa: Canadian Agencies for Drugs and Technologies in Health; 2006. Technology Report No.: 67.3.

12. De Luca G, Suryapranata H, Ottervanger JP, et al. Time delay to treatment and mortality in primary angioplasty for acute myocardial infarction: every minute of delay counts. Circulation 2004;109:1223-5.

13. Fibrinolytic Therapy Trialists' (FTT) Collaborative Group Indications for fibrinolytic therapy in suspected acute myocardial infarction: collaborative overview of early mortality and major morbidity results from all randomised trials of more than 1000 patients. Lancet 1994;343:311-22.

14. Eagle KA, Nallamothu BK, Mehta RH, et al. Trends in acute reperfusion therapy for ST-segment elevation myocardial infarction from 1999 to 2006: we are getting better but we have got a long way to go. Eur Heart 72008 ;29: 609-17.

15. Gibson CM, Pride YB, Frederick PD, et al. Trends in reperfusion strategies, door-to-needle and door-to-balloon times, and in-hospital mortality among patients with STsegment elevation myocardial infarction enrolled in the National Registry of Myocardial Infarction from 1990 to 2006. Am Heart 7 2008;156:1035-44.

16. Nallamothu BK, Wang Y, Bradley EH, et al. Comparing hospital performance in door-to-balloon time between the Hospital Quality Alliance and the National Cardiovascular Data Registry. $\mathcal{F}$ Am Coll Cardiol 2007;50:1517-9.

17. Tu JV, Donovan LR, Lee DS, et al. Quality of cardiac care in Ontario. Phase 1. Report 1. January 1, 2004. Available at: http://www.ccort.ca/EFFECT.aspx (accessed Jan 7, 2010).

18. Tu JV, Donovan LR, Austin PA, et al. Quality of cardiac care in Ontario. Phase I. Report 2. January 9, 2005. Available at: http://www.ccort.ca/EFFECT.aspx (accessed Jan 7, 2010).

19. Lee DS, Austin PC, Rouleau JL, et al. Predicting mortality among patients hospitalized for heart failure: derivation and validation of a clinical model. 7AMA 2003;290:2581-7.

20. Tu JV, Naylor CD, Austin P. Temporal changes in the outcomes of acute myocardial infarction in Ontario, 19921996. CMA7 1999;161:1257-61.

21. Alpert JS, Thygesen K, Antman E, et al. Myocardial infarction redefined-a consensus document of the Joint European Society of Cardiology/American College of Cardiology Committee for the redefinition of myocardial infarction. 7 Am Coll Cardiol 2000;36:959-69.

22. Herndon JE, Harrell FE Jr. The restricted cubic spline as baseline hazard in the proportional hazards model with step function time-dependent covariables. Stat Med 1995;14: 2119-29.

23. Austin PC, Tu JV, Daly PA, et al. The use of quantile regression in health care research: a case study examining gender differences in the timeliness of thrombolytic therapy. Stat Med 2005;24:791-816.

24. Bradley EH, Herrin J, Wang Y, et al. Strategies for reducing the door-to-balloon time in acute myocardial infarction. $N$ Engl 7 Med 2006;355:2308-20.

25. Atzema CL, Austin PC, Tu JV, et al. Emergency department triage of acute myocardial infarction patients and the effect on outcomes. Ann Emerg Med 2009;53:736-45.

26. Graff L, Palmer AC, Lamonica P, et al. Triage of patients for a rapid (5-minute) electrocardiogram: a rule based on presenting chief complaints. Ann Emerg Med 2000;36:55460.

27. Qasim A, Malpass K, O'Gorman DJ, et al. Safety and efficacy of nurse initiated thrombolysis in patients with acute myocardial infarction. BM7 2002;324:1328-31.

28. Eskola MJ, Nikus KC, Voipio-Pulkki LM, et al. Comparative accuracy of manual versus computerized electrocardiographic measurement of J-, ST- and T-wave deviations in patients with acute coronary syndrome. Am $\mathcal{F}$ Cardiol 2005;96:1584-8.

29. Massel D, Dawdy JA, Melendez LJ. Strict reliance on a computer algorithm or measurable ST segment criteria may lead to errors in thrombolytic therapy eligibility. Am Heart 7 2000;140:221-6. 
30. Ting HH, Krumholz HM, Bradley EH, et al. Implementation and integration of prehospital ECGs into systems of care for acute coronary syndrome: a scientific statement from the American Heart Association Interdisciplinary Council on Quality of Care and Outcomes Research, Emergency Cardiovascular Care Committee, Council on Cardiovascular Nursing, and Council on Clinical Cardiology. Circulation 2008;118:106679.

31. Canto JG, Zalenski RJ, Ornato JP, et al. Use of emergency medical services in acute myocardial infarction and subsequent quality of care: observations from the National Registry of Myocardial Infarction 2. Circulation 2002;106: 3018-23.

32. Williams DM. 2006 JEMS 200-city survey. EMS from all angles. FEMS 2007;32:38-42, 44, 46.

33. Schull MJ, Vaillancourt S, Donovan L, et al. Underuse of prehospital strategies to reduce time to reperfusion for STelevation myocardial infarction patients in 5 Canadian provinces. C7EM 2009;11:473-80.

34. Berger AK, Radford MJ, Krumholz HM. Factors associated with delay in reperfusion therapy in elderly patients with acute myocardial infarction: analysis of the cooperative cardiovascular project. Am Heart 7 2000;139:985-92.

35. Brophy JM, Diodati JG, Bogaty $\mathrm{P}$, et al. The delay to thrombolysis: an analysis of hospital and patient characteristics. Quebec Acute Coronary Care Working Group. CMA7 1998;158:475-80.

36. Newby LK, Rutsch WR, Califf RM, et al. Time from symptom onset to treatment and outcomes after thrombolytic therapy. GUSTO-1 Investigators. $7 \mathrm{Am}$ Coll Cardiol 1996;27:1646-55.

37. Magid DJ, Wang Y, Herrin J, et al. Relationship between time of day, day of week, timeliness of reperfusion, and in-hospital mortality for patients with acute ST-segment elevation myocardial infarction. 7AMA 2005;294:803-12.

38. Lambrew CT, Bowlby LJ, Rogers WJ, et al. Factors influencing the time to thrombolysis in acute myocardial infarction. Time to Thrombolysis Substudy of the National Registry of Myocardial Infarction-1. Arch Intern Med 1997; 157:2577-82.

39. Sharkey SW, Bruneete DD, Ruiz E, et al. An analysis of time delays preceding thrombolysis for acute myocardial infarction. FAMA 1989;262:3171-4.

40. Atzema CL, Austin P, Tu JV, Schull MJ. ED triage of patients with acute myocardial infarction: predictors of low acuity triage. Am 7 Emerg Med 2010;28:694-702.

41. Diercks DB, Kirk JD, Lindsell CJ, et al. Door-to-ECG time in patients with chest pain presenting to the ED. Am 7 Emerg Med 2006;24:1-7.

42. Parikh SV, Jacobi JA, Chu E, et al. Treatment delay in patients undergoing primary percutaneous coronary intervention for ST-elevation myocardial infarction: a key process analysis of patient and program factors. Am Heart $\mathcal{7} 2008$; 155:290-7.

43. McNamara RL, Herrin J, Bradley EH, et al. Hospital improvement in time to reperfusion in patients with acute myocardial infarction, 1999 to 2002. 7 Am Coll Cardiol 2006; 47:45-51.

44. Boden WE, Eagle K, Granger CB. Reperfusion strategies in acute ST-segment elevation myocardial infarction: a comprehensive review of contemporary management options. 7 Am Coll Cardiol 2007;50:917-29.

45. Tu JV, Donovan LR, Lee DS, et al. Effectiveness of public report cards for improving the quality of cardiac care: the EFFECT study: a randomized trial. FAMA 2009;302: 2330-7. 